\title{
Targets for Neoadjuvant Therapy - The Preferences of Patients with Early Breast Cancer
}

\author{
Therapieziele der neoadjuvanten Therapie - \\ Präferenzen von Patientinnen mit frühem Mammakarzinom
}

Authors

Affiliations
M. Thill ${ }^{1}$, G. Pisa ${ }^{2}$, G. Isbary ${ }^{3}$

${ }^{1}$ Klinik für Gynäkologie und Geburtshilfe, Agaplesion Markus-Krankenhaus Frankfurt, Frankfurt am Main

${ }^{2}$ Kantar Health, München

${ }^{3}$ Roche Pharma AG, Grenzach-Wyhlen
Key words

- early breast cancer

- neoadjuvant

- chemotherapy

- pathological complete remission ( $\mathrm{pCR}$ )

- patient preference

Schlüsselwörter

- frühes Mammakarzinom

- neoadjuvant

- Chemotherapie

- pathologische Komplettremission ( $\mathrm{PCR}$ )

- Patientenpräferenz

Deutsche Version unter: http://dx.doi.org/ 10.1055/s-0042-101025

\section{received $\quad 21.10 .2015$ \\ revised $\quad 20.12 .2015$ \\ accepted 17.1.2016}

Bibliography

DOI http://dx.doi.org/

10.1055/s-0042-101025

Geburtsh Frauenheilk 2016; 76 :

551-556 @ Georg Thieme

Verlag KG Stuttgart · New York . ISSN 0016-5751

\section{Correspondence}

\section{Dr. Marc Thill, MD, PhD}

Agaplesion Markus Hospital Department of Gynecology and Obstetrics

Wilhelm-Epstein-Straße 22

60431 Frankfurt am Main

marc.thill@t-online.de

\section{Abstract}

$\nabla$

Background: Therapists and administrative bodies consider a pathological complete remission as an independent and relevant endpoint in evaluations of the clinical utility of neoadjuvant therapy for early breast cancer. The present study aims to investigate which treatment outcomes of a neoadjuvant therapy are considered by the patients themselves to be relevant.

Materials and Methods: With the help of analytic hierarchy process (AHP) methods patient preferences about the treatment targets of neoadjuvant therapy were assessed quantitatively. All participants had undergone a neoadjuvant therapy in the form of chemotherapy and, in HER2-positive cases, as a targeted antibody therapy against HER2 for the primary diagnosis of early breast cancer 12-36 months prior to the interview. The criteria for the hierarchy model were identified in an earlier qualitative survey. The patient interviews were conducted by 4 experienced female interviewers.

Results: Forty-one patients participated in the quantitative survey, of these 15 (36.6\%) had suffered from HER2-positive disease. The achievement of pCR was the most important therapeutic target for the patients, even before disease-free survival, overall survival and the option for breast-preserving operation. Avoidance of side effects was considered to be the least important. In a comparison of the side effects the patients judged fatigue to be most important before nausea and loss of hair.

Conclusion: For the patients the achievement of a pathological complete remission is considered to be an independent, relevant and highly desired target of neoadjuvant therapy.

\section{Zusammenfassung \\ $\nabla$}

Hintergrund: Therapeuten und Behörden betrachten eine pathologische Komplettremission (pCR) als eigenständigen und relevanten Endpunkt zur Beurteilung des klinischen Nutzens einer neoadjuvanten Therapie beim frühen Mammakarzinom. Die vorliegende Studie sollte untersuchen, welche Behandlungsziele einer neoadjuvanten Therapie Patientinnen selbst als relevant erachten.

Material und Methodik: Mithilfe der AnalyticalHierarchy-Process-(AHP-)Methode wurden Patientenpräferenzen zu Behandlungszielen einer neoadjuvanten Therapie quantitativ gewichtet. Alle Probandinnen hatten eine neoadjuvante Therapie in Form einer Chemotherapie und bei HER2-Positivität einer zielgerichteten Antikörpertherapie gegen HER2 aufgrund der Primärdiagnose eines Mammakarzinoms 12-36 Monaten vor der Befragung erhalten. Die Kriterien des Hierarchiemodells wurden in einer vorangehenden qualitativen Befragung identifiziert. Die Patientinneninterviews wurden von 4 erfahrenen Interviewerinnen durchgeführt.

Ergebnisse: An der quantitativen Befragung nahmen 41 Patientinnen teil, davon 15 (36,6\%) mit HER2-positiver Erkrankung. Das Erreichen einer pCR stellte für die Patientinnen das wichtigste Therapieziel vor krankheitsfreiem Überleben, Gesamtüberleben und der Möglichkeit einer brusterhaltenden Operation dar. Der Vermeidung von Nebenwirkungen wurde die geringste Bedeutung zugemessen. Beim Vergleich der Nebenwirkungen hatte für die Patientinnen Fatigue den höchsten Stellenwert vor Übelkeit und Haarausfall.

Fazit: Das Erreichen einer pathologischen Komplettremission stellt für Patientinnen ein eigenständiges relevantes und vorrangiges Ziel einer neoadjuvanten Therapie dar. 


\section{Introduction}

Besides surgery, the therapy concept for patients with primary early breast cancer comprises chemotherapy in the presence of certain risk factors and, in HER2-positive cases, a targeted therapy against HER2 $[1,2]$. In the mean time we know that chemotherapy for early breast cancer, irrespective of an adjuvant or a neoadjuvant application, can achieve comparable long-term results with regard to disease-free survival and overall survival [3, 4]. As little as 15 years ago the rationale for neoadjuvant chemotherapy (NACT) consisted mainly in the preoperative reduction in volume of large primary tumours to achieve a better operability or to make a breast-preserving operation possible [5]. There is still a significant indication for NACT in cases of inflammatory tumours because of their aggressiveness and of inoperable or large operable breast cancers in dependence on their tumour biology/ characteristics. But furthermore, today neoadjuvant and adjuvant chemotherapies are equal alternative therapeutic options for early breast cancer $[1,2,6,7]$.

Basically NACT can be carried out when the indication for chemotherapy exists even before an operation $[1,2,7]$. Apart from improving the chances for a breast-preserving operation, it opens up further options. In contrast to adjuvant chemotherapy, it allows direct in vivo chemosensitivity testing and thus an evaluation of the response of the tumour and axillary lymph nodes to the systemic therapy in real time. In addition, it enables an individualisation of the therapy on the basis of response controls, on the one hand, by changing the chemotherapy and, on the other hand, by a risk-adapted post-neoadjuvant management [1]. Finally the response of the patient to a neoadjuvant therapy can provide additional prognostic information $[1,8]$.

The most important parameter for evaluating the success of a therapy is the pathological complete remission (pCR) [9]. This endpoint can directly reflect the effect of a neoadjuvant treatment. It is important to consider how the respective pCR is defined. The most frequently used definitions are ypT0 ypNO (no residual invasive and in situ tumour remains in the breast and axilla), ypT0/is ypNO (no residual invasive tumour remains in the breast and axilla, independent of an in situ component also known as tpCR) and ypT0/is (no residual invasive tumour remains in the breast, independent of axillary lymph node attack or an in situ carcinoma).

In various trials and meta-analyses a relationship at the patient level between the achievement of $\mathrm{PCR}$ and a longer overall survival has been demonstrated $[4,10,11]$. Also in a large meta-analysis of 12 trials initiated by the US drug registration authority FDA with a total of 11955 patients, an association between achievement of pCR and an improved, event-free survival was observed. Here, the prognostic significance was highest for triple negative breast cancers and HER2-positive, HR-negative tumours treated with trastuzumab. A formal validation of PCR as a surrogate marker for an improved, event-free survival and overall survival was not possible at the trial level in this very heterogeneous patient collective [12].

Therapists and the American as well as the European drug registration authorities consider PCR to be an independent and relevant endpoint for evaluating the clinical efficacy of neoadjuvant therapy. The present study is intended to investigate which treatment targets of neoadjuvant therapy the patients themselves consider to be relevant.

\section{Materials and Methods}

$\boldsymbol{\nabla}$

\section{Patient recruitment}

Patient recruitment was by personal contact, internet advertisements, information flyers to sport groups and apothecaries, direct enrolment from a database and contact through an already enrolled person.

\section{Interviewers}

The interviews were carried out by a total of four female interviewers. They were permanent employees of a market research company with 5-10 years of experience in conducting interviews with patients and physicians.

\section{Qualitative survey}

Nation-wide in Germany in-depth interviews with 8 patients were conducted with the aim to confirm the completeness and unambiguous definition of the relevant preferences and to exclude any overlap between the preferences.

The patients had all undergone neoadjuvant therapy in the form of chemotherapy and, in the case of HER2-positive disease, a targeted antibody therapy against HER2. Further prerequisites that had to be confirmed by the patients themselves were an interval of $>12$ months since the primary diagnosis of breast cancer and between $>12$ and $<36$ months since tumour surgery.

The interviews were held in the patient's home and were based on a structured interview guide. The guideline consisted of 12 main questions with $0-5$ subitems and was split into 2 chapters. Information about the patient's medical history and about the relevance of various features of the neoadjuvant therapy was recorded. The interview lasted about 60 minutes.

\section{Evaluation of the in-depth interviews}

The qualitative interviews were recorded digitally and transcribed from the record. Evaluation of the interview protocol was done analogously to that of the summarised qualitative content analysis [13].

\section{Quantitative survey}

41 patients were interviewed nation-wide in Germany. The age of the patients was initially recorded in cumulative categories (under $45,45-60,61-70$, over 70 years). In a second step the exact age was recorded. Each patient had to have undergone a neoadjuvant therapy in the form of chemotherapy as well as, in the case of HER2-positive disease, a targeted antibody therapy against HER2. Further inclusion criteria that had to be confirmed by the patients were an interval of $>6$ months since the primary diagnosis of breast cancer and between $>12$ and $<36$ months since tumour surgery. The required minimum interval between interview and primary diagnosis was reduced from 12 to 6 months on account of the slow recruitment of the first 8 patients for the qualitative survey. The interviews were computer-assisted (computer-aided personal interview), held in the patient's home and lasted for about 30 minutes.

The patients' preferences were determined with the help of analytic hierarchy process (AHP) methods [14-16]. This multicriterial decision method structures complex decision-making processes. The hierarchical levels and criteria are presented in 0 Table 1. The thematic classification of therapeutic attributes to hierarchical levels was made on the basis of the qualitative interviews. The criteria were described in analogy to the terms used 
Table 1 Criteria of the used AHP designs.
Hierarchical level 0
Hierarchical level 1
Hierarchical level 2
1. Efficacy of the neoadjuvant therapy
1. Destruction of tumour cells*
2. Minimisation of the risk for tumour recurrence*
3. No reduction of life expectancy due to the disease*
4. Possibility for breast-preserving operation
2. Avoidance of side effects of the neoadjuvant therapy
5. Side effects that are stressful for the body
1. Fever
2. Diarrhoea
3. Nausea
4. Fatigue
6. Side effects that cause bodily changes
5. Loss of hair
6. Weight gain
The criteria were determined in 8 qualitative patient interviews and formulated in the words used by the patients instead of specialist medical terms.
* "Destruction of tumour cells" = pathological complete response ( $\mathrm{pCR}), 2$ : "Minimisation of the risk for tumour recurrence" = disease-free survival (DFS), 3: "No reduction of life expectancy due to the disease" $=$ overall survival (OS).

by the patients in the qualitative interviews and not in the form of specialist medical terms.

First of all the patients had to compare the criteria of hierarchical level 1 pair-wise with one another and then the subcriteria of hierarchical level 2 within the defined hierarchical model ( $\bullet$ Table 1). In order to increase the attentiveness of the participants and to avoid answer patterns, 15 pair comparisons per level were doubly randomised. This means that the order in which the pair comparisons were presented to the patients and the position of the criterion to be compared were arbitrary. In the process the participant stated which of the two criteria to be compared was the more important for her and to what extent this criterion was more important than the other one for her. The evaluation of importance was done in a semiquantitative manner using a ninepoint scale where 1 point is the indifference point and 9 points corresponds to the highest scoring. The scale steps with points $1,3,5,7$ and 0 were verbally designated as identical, somewhat larger, considerably larger, very much larger and absolutely dominating.

In the data set each pair comparison A vs. B was assigned a value by the answer which could be $1 / 9$ (= criterion $B$ absolutely dominating) for a large significance for criterion $B, 1 / 8,1 / 7,1 / 6,1 / 5$, $1 / 4,1 / 3$ or $1 / 2$, down to $1 / 1$ for equal significance of criteria $A$ and $\mathrm{B}$. The answers of the 41 female participants were summarised to a sample mean score. For each pair comparison the geometrical mean for all 41 answers was derived. In this mathematical process as well as in all other methodological aspects, the study was oriented on the stipulations of the pilot project from the Institute for Quality and Economy in the Health Service (Institut für Qualität und Wirtschaftlichkeit im Gesundheitswesen [IQWiG]) regarding the analytic hierarchy process [17].

The results of the 2 AHP hierarchical levels were evaluated separately. For this the sample mean scores of all 30 pair comparisons were transferred to two AHP matrices. With the help of the AHP function of the PMR package in statistics software $R$, the criterion weightings and the consistency of the AHP matrix were calculated [18]. Using the consistency ratio according to Saaty [15, $16]$, we checked whether the preferences revealed by the comparisons were consistent with the other comparisons [17].

From the weightings of the hierarchical levels 1 and 2 the results of the entire - comprising three levels $(0,1,2)$ - AHP model were determined. For this the hierarchical level 0 was derived from the sum of the weightings of hierarchical level 1 . In the entire model the individual subcriteria of hierarchical level 2 were contained in the relative weightings to each other and their sum gave the weighting of hierarchical level 2.

\section{Results \\ $\nabla$ \\ Qualitative survey}

Eight patients aged between 30 and 78 years took part in the qualitative interviews. Two of these patients had had an HER2positive breast cancer.

In the interviews it was clear that the efficacy of the neoadjuvant therapy represented the most important therapeutic criterion for the patients. The patients mentioned the destruction of tumour cells, reduction of the risk of recurrence, no shortening of life expectancy due to the disease, and the possibility for breast-preserving surgery as criteria for the efficacy. The endpoints $\mathrm{pCR}$, disease-free survival and overall survival from clinical studies are reflected in the qualitative patient survey by the criteria "destruction of tumour cells", "minimisation of the risk for tumour recurrence" and "no shortening of life expectancy due to the disease".

The side effects of the therapy were also important for the patients, although they were widely accepted as part of the price for an effective drug. Even so they were considered to be a burden that the patients would happily do without. The patients also assessed their quality of life mainly in dependence of the presence of side effects.

\section{Quantitative survey}

The results of the quantitative interviews of 41 patients, among whom 15 (36.6\%) had had HER2-positive disease, were available. The patients came from 13 federal states: 7 from Baden-Württemberg, 3 from Bavaria, 1 from Bremen, 4 from Hamburg, 1 from Hesse, 1 from Mecklenburg-Western Pomerania, 4 from Lower Saxony, 9 from North Rhine-Westphalia, 3 from Saxony, 2 from Saxony-Anhalt, 1 from Schleswig-Holstein and 2 from Thuringia. 27 patients (65.8\%) were between 45 and 70 years old. $14.6 \%$ were older than 70 years and $19.5 \%$ younger than 45 years. For seven patients we only knew that they were either younger than 45 years $(n=1)$, between 45 and 60 years $(n=5)$ or, respectively, between 61 and 70 years old $(n=1)$. Apart from this, the interviewers did not get any more detailed information about their ages. For the other 34 participants in the study the exact ages were known with a median value of 50 years (range 29-76 years). For 9 patients $(22.0 \%)$ the primary diagnosis was made $6-12$ 
Table 2 Demographic data.

\begin{tabular}{|llc|}
\hline $\begin{array}{l}\text { Characteristic } \\
\text { Age* }\end{array}$ & Median (Range), years & $50(29-76)$ \\
\hline $\begin{array}{l}\text { Interval between primary } \\
\text { diagnosis and interview }\end{array}$ & $6-12$ months & $9(22.0)$ \\
\hline & $13-24$ months & $13(31.7)$ \\
\hline & $\geq 24$ months & $19(46.3)$ \\
\hline HER2 status & positive & $15(36.6 \%)$ \\
\hline & negative & $26(63.4 \%)$ \\
\hline
\end{tabular}

* Median age and range for 34 patients. For 7 patients it was merely known that their ages were either under 45 years $(n=1)$, between 45 and 60 years $(n=5)$ or, respectively, between 61 and 70 years $(n=1)$.
Table 3 Group weightings in hierarchical level 1.

\begin{tabular}{|c|c|c|}
\hline Therapeutic target of neoadjuvant therapy & Weighting & $\begin{array}{l}\text { Consis- } \\
\text { tency } \\
\text { ratio }\end{array}$ \\
\hline Sum of group weightings & 1.00 & 0.007 \\
\hline Destruction of tumour cells & 0.316 & \\
\hline Minimisation of the risk for tumour recurrence & 0.256 & \\
\hline $\begin{array}{l}\text { No shortening of life expectancy due to } \\
\text { the disease }\end{array}$ & 0.241 & \\
\hline Possibility for breast-preserving surgery & 0.099 & \\
\hline Avoidance of side effects causing bodily burdens & 0.050 & \\
\hline Avoidance of side effects causing bodily changes & 0,038 & \\
\hline
\end{tabular}

The weightings were determined from the sample mean values of the pair-wise comparison of the criteria in hierarchical level 1 by all 41 patients. The consistency ratio according to Saaty [17] checks whether the individual pair-wise comparisons are consistent with all the other comparisons.

Table 4 Group weightings of all hierarchical levels.

\begin{tabular}{|c|c|c|c|c|}
\hline \multirow[t]{2}{*}{ Therapeutic targets of neoadjuvant therapy } & \multicolumn{3}{|c|}{ Group weightings according to hierarchical level } & \multirow[t]{2}{*}{ Consistency ratio } \\
\hline & 0 & 1 & 2 & \\
\hline Efficacy & 0.912 & & & 0.007 \\
\hline Destruction of tumour cells & & 0.316 & & \\
\hline - Minimising the risk for tumour recurrence & & 0.256 & & \\
\hline - No shortening of life expectancy due to the disease & & 0.241 & & \\
\hline Possibility for breast-preserving operation & & 0.099 & & \\
\hline Avoidance of side effects & 0.088 & & & 0.005 \\
\hline Side effects that cause bodily burdens & & 0.050 & & \\
\hline Fever & & & 0.011 & \\
\hline D Diarrhoea & & & 0.008 & \\
\hline D Nausea & & & 0.015 & \\
\hline Fatigue & & & 0.016 & \\
\hline Side effects that cause bodily changes & & 0.038 & & \\
\hline Loss of hair & & & 0.022 & \\
\hline - Weight gain & & & 0.016 & \\
\hline
\end{tabular}

From the weightings of the hierarchical levels 1 and 2, the results of the entire AHP model encompassing all three levels were derived. Here the hierarchical level 0 is determined from the sums of the weightings of hierarchical level 1. The individual subcriteria of the hierarchical level 2 are obtained in their relative weightings to each other in the entire model and give in their sum the weighting of hierarchical level 2.

months prior to the interview, for 13 (31.7\%) 13-24 months earlier and for 19 (46.3\%) more than 24 months before the interview (O Table 2).

The efficacy of the neoadjuvant therapy was more important for the patients than the avoidance of side effects. On comparison of the criteria in the second hierarchical level the group weightings of all efficacy criteria were above those of side effects. The elimination of tumour cells, or in medical specialist terminology the pathological complete remission represented for the patients the most important therapeutic target on account of its highest group weighting (0.316). The reduction of the risk of recurrence and thus disease-free survival $(0.256)$ and no shortening of life expectancy due to the disease (0.241) followed in second and third places before the possibility for a breast-preserving operation. Avoidance of side effects was considered to be the least important criterion: group weighting of 0.050 for side effects that cause a burden for the body, and 0.038 for those that cause bodily changes ( 0 Table $\mathbf{3}$ ).

With a weighting of 0.912 the superordinate therapeutic target efficacy of neoadjuvant therapy gains a clear preference over the superordinate therapeutic target avoidance of side effects with a weighting of 0.088 ( $\odot$ Table 4 ).
Table 5 Group weightings of hierarchical level 2.

\begin{tabular}{lll}
$\begin{array}{l}\text { Therapeutic target of neoadjuvant } \\
\text { therapy }\end{array}$ & Weighting & $\begin{array}{l}\text { Consistency } \\
\text { ratio }\end{array}$ \\
Sum of group weights & 1.00 & 0.005 \\
\hline Avoidance of fatigue & 0.225 & \\
\hline Avoidance of nausea & 0.202 & \\
\hline Avoidance of loss of hair & 0.181 & \\
\hline Avoidance of fever & 0.148 & \\
\hline Avoidance of weight gain & 0.138 & \\
\hline Avoidance of diarrhoea & 0.106 & \\
\hline
\end{tabular}

The weightings were determined from the sample mean values of the pair-wise comparisons of the criteria in hierarchical level 1 by all 41 patients. The consistency ratio according to Saaty [17] checks whether the individual pair-wise comparisons are consistent with all the other comparisons.

On comparison of the subcriteria in hierarchical level 2, the patients gave the top priority to the avoidance of fatigue (0.225) followed by avoidance of nausea (0.202) and loss of hair (0.181) (๑ Table 5). 


\section{Discussion}

$\nabla$

There are studies on patient preferences for chemotherapy. However, to the best of our knowledge as yet no specific investigation of the preferences of patients with regard to neoadjuvant therapy has yet been published.

We chose the AHP method to determine patient preferences. This is an instrument developed by the mathematician Saaty more than 30 years ago that also finds use in decision-making processes in the health-care services $[19,20]$. According to a pilot project of IQWiG for patients with the diagnosis "depression", it was shown to be a very structured and easily implemented procedure for the quantitative measurement of patient preferences and it also provides important tips about suitable endpoints for clinical trials [17]. The method has also been used to deduce the preferences of patients with cancer diseases [21-23].

The patients in our study on the whole assigned more importance to the efficacy of a neoadjuvant therapy as well as to all four efficacy parameters than to the avoidance of side effects. This result is reasonable on account of the early stage of their disease and the curative therapy options. This observation is also in accord with those of other studies in which the effectiveness of a therapy is of the greatest importance for patients with breast cancer [24] and where the maintenance of an as high as possible quality of life becomes more important in advanced stages [25]. In the present study the patients mentioned treatment targets for the neoadjuvant therapy that corresponded precisely with the endpoints of clinical trials. This suggests that the endpoints investigated in this study: $\mathrm{PCR}$, disease-free survival, and overall survival can be directly classified as being patient relevant. One could argue that this is not the uninfluenced opinion of the patients but rather the repetition of acquired knowledge. In the event, the patients had had access to information from the consultations with the responsible physician in the framework of the decision-making process for the neoadjuvant therapy as well as other available information material. The patients could then compare this knowledge with their own experiences in the course of the neoadjuvant therapy which, in our opinion, rather supports the conclusion about the patient relevance of the respective endpoints.

More generally, the question arises to what extent the preferences determined in this study correspond with those of newly diagnosed cancer patients without any neoadjuvant therapy since the actual experiences with neoadjuvant therapy could have influenced the perspectives of the interviewed patients. Other studies have shown that the therapeutic preferences of patients with early breast cancer depend less on experience with chemotherapy but rather much more on their basic attitudes to chemotherapy prior to commencement of the therapy [26,27].

In our study the achievement of PCR was the most highly preferred treatment target of neoadjuvant therapy. Also for the physician PCR is the most important parameter to evaluate the success of neoadjuvant therapy [9]. The crucial factor here is the association between $\mathrm{pCR}$ and an improved survival at the patient level as demonstrated in clinical studies and meta-analyses $[4,10$, 11 , even when the formal validation of $\mathrm{PCR}$ as a surrogate marker for survival has not yet been established due to a lack of evidence at the study level [12]. Our investigation does not allow any conclusions about the extent to which patients consider pCR as a surrogate marker for disease-free survival or overall survival. It does show that the patients recognise PCR together with disease-free survival, overall survival, and breast-preserving opera- tions as independent and personally relevant endpoints. For the patients, pCR has the highest significance. This can possible be explained by the fact that the patient directly experiences and can understand her response to therapy as the thus resulting complete elimination of tumour cells. She thereby probably associates this also with the destruction of circulating tumour cells and thus potential focus points for metastasis in her body.

Two other studies on patient preferences in chemotherapy for breast cancer named an extension of overall survival as the major treatment target of chemotherapy. However, apart from the preference of the patients for efficacy in chemotherapy, they are only difficultly comparable. They included breast cancer patients in disease stages I to IV, for example. In one study in total 11 criteria were evaluated, including merely overall survival as an efficacy parameter beside 10 side effect criteria [24]. In the second study, prolongation of overall survival was judged to be more important than delaying disease progression without survival benefit, delaying disease progression per se, and maintenance of a higher quality of life [25].

The perspectives of the patient towards neoadjuvant therapy have been taken into account with the new official registration practice. On the basis of the existing evidence, the FDA now accepts pCR as endpoint for an accelerated approval of therapies for early breast cancer [8]. The first approval on the basis of this regulation was granted in 2013 for neoadjuvant therapy using pertuzumab with trastuzumab and chemotherapy [28]. Also the European drug approval authority EMA gave its approval for pertuzumab as first drug to be used in neoadjuvant therapy for early breast cancer in July 2015 on the basis of the endpoint pCR [29]. The major strength of our study is the dedicated patient interviewing carried out by means of personally conducted, comprehensive interviews by experienced interviewers. Our study, that provides a quantitative weighting of patient preferences, also exhibits some limitations. It acquired its information exclusively from patient interviews that focussed on the acquisition of quantitative preferences. Detailed information on patient and tumour characteristics as well as the employed therapy regimes was thus not systematically collected. Thus it remains unclear if and what influence these factors had on the patients' evaluation. In this context it would also have been interesting to learn from a parallel survey of the responsible physicians to what extent the preferences of the patients agreed with those of their physicians.

\section{Practical Conclusions \\ $\nabla$}

For the patients the achievement of pCR represents an independent, relevant and highly desirable goal of neoadjuvant therapy.

\section{Disclosure \\ $\nabla$}

In the preparation of this manuscript the authors received editorial assistance from Dr. Susanne Hell, supported by an unrestricted grant from Roche Pharma AG. All statements in the text reflect the opinions of all of the authors.

\section{Conflict of Interest \\ $\nabla$}

M. Thill received fees for talks and advisory services and compensation for travel expenses by Roche. 


\section{References}

1 AGO. Diagnostik und Therapie primärer und metastasierter Mammakarzinome: Version 2015. 1D. 03.2015. Online: http://www.agoonline.de/de/fuer-mediziner/leitlinienempfehlungen/mamma/; last access: 20.08.2015

2 DKG. Interdisziplinäre S3-Leitlinie für die Diagnostik, Therapie und Nachsorge des Mammakarzinoms. Langversion 3.0. Online: http:// www.krebsgesellschaft.de/download/S3_Brustkrebs_Update_2012_ OL_Langversion.pdf; last access: 20.08.2015

3 Mauri D, Pavlidis N, Ioannidis JP. Neoadjuvant versus adjuvant systemic treatment in breast cancer: a meta-analysis. J Natl Cancer Inst 2005; 97: 188-194

4 Rastogi P, Anderson SJ, Bear HD et al. Preoperative chemotherapy: updates of National Surgical Adjuvant Breast and Bowel Project Protocols B-18 and B-27. J Clin Oncol 2008; 26: 778-785

5 Kaufmann M, von Minckwitz G, Mamounas EP et al. Recommendations from an international consensus conference on the current status and future of neoadjuvant systemic therapy in primary breast cancer. Ann Surg Oncol 2012; 19: 1508-1516

6 NCCN Clinical Practice Guidelines in Oncology - Breast Cancer, Version 2. 2015. Last access: 30.07 .2015

7 Cardoso F, Costa A, Norton L et al. ESO-ESMO 2nd international consensus guidelines for advanced breast cancer (ABC2). Ann Oncol 2014; 25 : $1871-1888$

8 U.S. Department of Health and Human Services Food and Drug Administration; Center for Drug Evaluation and Research (CDER). FDA guidance for industry pathological complete response in neoadjuvant treatment of high-risk early-stage breast cancer: use as an endpoint to support accelerated approval, Oktober 2014. Online: http://www.fda.gov/ downloads/drugs/guidancecomplianceregulatoryinformation/ guidances/ucm305501.pdf; last access: 21.08.2015

9 Untch M, Konecny GE, Paepke S et al. Current and future role of neoadjuvant therapy for breast cancer. Breast 2014; 23: 526-537

10 Mieog JS, van der Hage JA, van de Velde CJ. Preoperative chemotherapy for women with operable breast cancer. Cochrane Database Syst Rev 2007; 2: CD005002

11 von Minckwitz G, Untch M, Blohmer JU et al. Definition and impact of pathologic complete response on prognosis after neoadjuvant chemotherapy in various intrinsic breast cancer subtypes. J Clin Oncol 2012; 30: 1796-1804

12 Cortazar P, Zhang L, Untch $M$ et al. Pathological complete response and long-term clinical benefit in breast cancer: the CTNeoBC pooled analysis. Lancet 2014; 384: 164-172

13 Mayring P. Qualitative Inhaltsanalyse, Grundlagen und Techniken. 10. Aufl. Weinheim: Beltz; 2008
14 Ijzerman MJ, van Til JA, Snoek GJ. Comparison of two multi-criteria decision techniques for eliciting treatment preferences in people with neurological disorders. Patient 2008; 1: 265-272

15 Saaty TL. The analytic Hierarchy Process: Planning, Priority Setting, Resource Allocation. 2nd ed. New York: McGraw-Hill; 1980: XIII, 287

16 Saaty TL. A scaling method for priorities in hierarchical structures. J Math Psychol 1977; 15: 234-281

17 Danner M. Analytic hierarchy process (AHP) - Pilotprojekt zur Erhebung von Patientenpräferenzen in der Indikation Depression. 2013. Online: https://www.iqwig.de/download/Arbeitspapier_Analytic-Hierarchy-Process_Pilotprojekt.pdf; last access: 21.08.2015

18 Lee, PH, Yu PLH. Probability models for ranking data. DGHO Onkopedia Mammakarzinom der Frau. 2014. Online: http://cran. r-project.org/web/packages/pmr/index.html; last access: 07.05.2015

19 Dolan JG, Isselhardt BJ, Cappuccio JD. The analytic hierarchy process in medical decision making - a tutorial. Med Decis Making 1989; 9: 4050

20 Dolan JG. Medical decision making using the analytic hierarchy process: choice of initial antimicrobial therapy for acute pyelonephritis. Med Decis Making 1989; 9: 51-56

21 Dolan JG, Boohaker E, Allison J et al. Patients' preferences and priorities regarding colorectal cancer screening. Med Decis Making 2013; 33: $59-70$

22 Carter KJ, Ritchey NP, Castro F et al. Analysis of three decision-making methods: a breast cancer patient as a model. Med Decis Making 1999; 19: 49-57

23 Xu Y, Levy BT, Daly JM et al. Comparison of patient preferences for fecal immunochemical test or colonoscopy using the analytic hierarchy process. BMC Health Serv Res 2015; 15: 175

24 Beusterien K, Grinspan J, Tencer T et al. Patient preferences for chemotherapies used in breast cancer. Int J Womens Health 2012; 4: 279-287

25 Kuchuk I, Bouganim N, Beusterien Ket al. Preference weights for chemotherapy side effects from the perspective of women with breast cancer. Breast Cancer Res Treat 2013; 142: 101-107

26 Jansen SJ, Kievit J, Nooij MA et al. Patients' preferences for adjuvant chemotherapy in early-stage breast cancer: is treatment worthwhile? $\mathrm{Br}$ J Cancer 2001; 84: 1577-1585

27 Jansen SJ, Otten W, Baas-Thijssen MC et al. Stability of preferences with regard to adjuvant chemotherapy: impact of treatment decision, experience and the passing of time. Eur J Cancer Care (Engl) 2008; 17: 7483

28 FDA Pressemitteilung vom 30.09.2013. Online: http://www.fda.gov/ NewsEvents/Newsroom/PressAnnouncements/ucm370393.htm; last access: 21.08.2015

29 Roche Pressemitteilung vom 31.07.2015. Online: http://www. roche.com/media/store/releases/med-cor-2015-07-31.htm; last access: 21.08 .2015 